\title{
Avaliação de um secador solar em diferentes condições climáticas e meteorológicas
}

\author{
Evaluation of a solar dryer in different climatic and meteorological conditions \\ Evaluación de un secador solar en diferentes condiciones climáticas y meteorológicas
}

Recebido: 06/12/2021 | Revisado: 12/12/2021 | Aceito: 22/12/2021 | Publicado: 04/01/2022

\author{
Michel Barros Silva \\ ORCID: https://orcid.org/0000-0003-2303-4943 \\ Universidade Federal de Campina Grande, Brasil \\ E-mail: michelbarrosufcg@hotmail.com
}

\begin{abstract}
Resumo
O Nordeste brasileiro destaca-se, entre outros aspectos, pela produção de frutas e pela disponibilidade de energia solar. No entanto, a produção de frutas secas nessa região do país ainda não é expressiva. Estudos sobre a secagem de alimentos vêm sendo desenvolvidos em todo mundo, já que o processo de secagem tradicional em estufa demanda grandes investimentos e alto consumo de energia elétrica, elevando o custo do produto final. A secagem solar em equipamentos construídos com materiais de baixo custo e cuja operação e manutenção possam ser executadas sem necessidade de ações de elevada complexidade, torna-se uma tecnologia apropriada para a agricultura familiar. $\mathrm{O}$ objetivo deste trabalho foi comparar o desempenho de um secador solar de exposição indireta em climas e condições meteorológicas distintas. Para tanto, testes experimentais de secagem foram realizados, na secagem de banana prata, nas cidades de campina Grande, PB e Pombal, PB em períodos de maior e menor intensidade de radiação solar. Foi possível observar a influência das condições de temperatura e umidade relativa do ar ambiente e da incidência de radiação solar no tempo de secagem. Obteve-se rendimento térmico médio de 30,04\% e tempo médio de secagem de 13,5 horas, resultados similares aos reportados na literatura.
\end{abstract}

Palavras-chave: Secador solar; Rendimento térmico; Banana; Secagem.

\begin{abstract}
The Brazilian Northeast stands out, among other things, for its fruit production and the availability of solar energy. However, the production of dried fruit in this region of the country is still not expressive. Studies on food drying have been developed around the world, since the traditional drying process in an oven requires large investments and high electricity consumption, increasing the cost of the final product. Solar drying in equipment built with low-cost materials and whose operation and maintenance can be performed without the need for highly complex actions, becomes an appropriate technology for family farming. The objective of this work was to compare the performance of an indirect exposure solar dryer in different climates and meteorological conditions. For that, experimental drying tests were carried out, in the drying of silver bananas, in the cities of Campina Grande, PB and Pombal, PB, in periods of greater and lesser intensity of solar radiation. It was possible to observe the influence of the temperature and relative humidity conditions of the ambient air and the incidence of solar radiation on the drying time. Average thermal yield of $30,04 \%$ and average drying time of 13,5 hours were obtained, results similar to those reported in the literature.
\end{abstract}

Keywords: Solar dryer; Thermal yield; Banana; Drying.

\section{Resumen}

El Nordeste brasileño se destaca, entre otras cosas, por su producción de frutas y la disponibilidad de energía solar. Sin embargo, la producción de frutos secos en esta región del país aún no es expresiva. Se han desarrollado estudios sobre el secado de alimentos en todo el mundo, ya que el proceso tradicional de secado en horno requiere grandes inversiones y un alto consumo eléctrico, aumentando el costo del producto final. El secado solar en equipos construidos con materiales de bajo costo y cuya operación y mantenimiento se puede realizar sin necesidad de acciones de alta complejidad, se convierte en una tecnología apropiada para la agricultura familiar. El objetivo de este trabajo fue comparar el desempeño de un secador solar de exposición indirecta en diferentes climas y condiciones meteorológicas. Para ello, se realizaron pruebas experimentales de secado, en el secado de banano plateado, en las ciudades de Campina Grande, PB y Pombal, PB, en períodos de mayor y menor intensidad de radiación solar. Se pudo observar la influencia de las condiciones de temperatura y humedad relativa del aire ambiente y la incidencia de la radiación solar en el tiempo de secado. Se obtuvieron rendimiento térmico promedio de 30,04\% y tiempo de secado promedio de 13,5 horas, resultados similares a los reportados en la literatura.

Palabras clave: Secador solar; Rendimiento térmico; Banana; El secado. 


\section{Introdução}

Secagem é um processo simultâneo de transferência de calor e massa entre o ar e o produto a ser seco. Energia, em forma de calor, é transferido para o produto, enquanto vapor de água é transferido para o ar circundante (Lima, 1999, Costa, 2008).

Lima (1999) ressalta ainda que, no processo de secagem, é necessário fornecer calor ao material úmido para que a água possa ser transportada do interior do sólido até sua superfície; permitindo, assim, sua evaporação da superfície do material para o ambiente.

Estudos sobre a secagem de alimentos vêm sendo desenvolvidos em todo mundo, já que o processo de secagem tradicional em estufa demanda grandes investimentos e alto consumo de energia elétrica, elevando o custo do produto final e dificultando seu acesso aos produtores ruais de pequena escala.

Segundo Silva e Sousa (2020), a energia solar se tornou uma das formas de energia alternativa mais utilizadas, por ser uma fonte renovável e não poluente.

Segundo Nunes (2016), secadores solares usam fontes de energia livres e renováveis, reduzem as perdas de secagem (em comparação com a secagem direta ao sol) e apresentam custos operacionais demasiadamente mais baixos que a secagem elétrica.

Segundo a ABRAFRUTA (2019), o Brasil é o terceiro maior produtor mundial de frutas. E, segundo a CRESESB (2019), possui áreas com incidência de irradiação solar comparáveis as melhores do mundo com destaque para o Nordeste brasileiro.

Segundo a FAO (2017), cerca de um terço da produção mundial de alimentos é perdida ou desperdiçada em alguma etapa entre o plantio e a comercialização. Quando se trata de frutas e hortaliças, o percentual de desperdício pode chegar a $50 \%$.

A secagem é um dos métodos mais antigos métodos de conservação de alimentos e tem por finalidade adiar ou mesmo evitar as reações químicas e os processos microbiológicos como desenvolvimento e proliferação de fungos e bactérias aumentando assim a vida útil do produto e mantendo suas propriedades nutricionais.

O processo de secagem apresenta-se, então, como uma alternativa para a conservação de alimentos e a secagem solar apresenta-se como alternativa aos métodos de secagem natural, cujos parâmetros de secagem não podem ser controlados, e a secagem artificial em estufa, que possui elevado custo de investimento, operação e manutenção.

O secador é o equipamento usado com a finalidade de reduzir a umidade dos produtos através ação do calor. O secador solar é o equipamento que promove a secagem de um determinado produto utilizando como fonte primaria de calor a energia solar térmica.

Nos últimos anos, a secagem utilizando secador solar tem crescido por ter apresentado resultados positivos quanto ao processo de secagem e a qualidade final do produto. Isso se deve a diversas pesquisas onde estão sendo propostos secadores solares em diversas configurações, construídos de diferentes tipos de materiais isolantes térmico e grande variedade de tipos e formatos de cobertura transparente no intuito de intensificar o ganho de calor pelo ar de secagem e, consequentemente, otimizar o processo de secagem. Pode-se citar trabalhos como (Nunes, 2016, Fudholi 2014, Costa et al 2021, Fernandes 2021, Gomes 2021).

$\mathrm{O}$ ar ambiente ao entrar e passar pelo coletor solar é aquecido devido o contato com as faces internas do coletor que foram previamente aquecidas pelo efeito estufa que ocorre dentro do coletor solar, o efeito estufa, por sua vez, foi provocado pela incidência de radiação solar que atravessa a cobertura transparente do coletor e, ao mudar seu comprimento de onda, fica "preso" no coletor, fazendo sua temperatura se elevar. Ao ganhar energia em forma de calor, o ar aumenta sua temperatura e reduz sua umidade relativa. 
A banana é produzida em todas as regiões brasileiras, em diferentes condições de clima, solo e níveis de produção, com maior destaque nas regiões Nordeste e Sudeste. Pode ser consumida in natura, frita, assada, cozida, em calda, em passas, como doces caseiros ou em produtos industrializados.

A banana madura, em geral, apresenta $19 \%$ de açúcares e $1 \%$ de amido. O fruto é basicamente composto de: água (70\%); proteína (1,2\%); carboidrato rico em fósforo (27\%), apresentando regular teor de cálcio, ferro, cobre, zinco, iodo, manganês e cobalto, vitamina A, tiamina, riboflavina, niacina e vitamina C (LIMA, 1999). O auto teor de água inicial promove o crescimento microbiano, o que causa a degradação das suas características sensoriais, levando à perda do valor nutricional e, por conseguinte, perda no valor comercial.

Em 2020, o Nordeste foi responsável por grande parte da produção nacional de banana, com destaque para o estado da Bahia (IBGE, 2020).

As frutas desidratadas representam uma fonte concentrada de calorias, fibras, vitaminas, açúcar natural e alguns nutrientes, além de terem um prazo de validade muito maior que as frutas frescas, devido à diminuição da concentração da água no produto.

O processo de secagem permite estabilizar a atividade microbiológica e reduzir as reações químicas e enzimáticas, permitindo a disponibilidade do fruto durante todo o ano, além de reduzir sua massa e, consequentemente, os custos de transporte e de armazenamento, sem afetar suas características organolépticas nem sua qualidade nutricional.

\section{Metodologia}

O secador solar desenvolvido possui coletor solar, câmara de secagem e um sistema de exaustão para convecção forçada do ar acionado por painel solar fotovoltaico. Trata-se de uma pesquisa experimental cuja metodologia tem suporte nos trabalhos de Nunes (2016), Lima (2017), Gomes (2021), Leite Filha et al. (2021).

\subsection{Coletor solar}

Segundo Oliveira et al., (2018) o coletor solar é o principal componente de um secador solar, uma vez que atua diretamente na captação da radiação solar e sua posterior conversão em energia térmica.

O coletor solar plano foi construído a partir do trabalho de Leite Filha et al. (2021). Neste trabalho, os pesquisadores estudaram a configuração ótima para um coletor solar plano, aplicando a metodologia planejamento experimental fatorial.

O equipamento foi construído com polietileno estendido (isopor) de $0,025 \mathrm{~m}$, revestido internamente e externamente com alumínio, pintado internamente de preto fosco, possuindo, internamente: $0,80 \mathrm{~m}$ de largura, 1,25 m de comprimento e 0,10 m de altura, totalizando um volume de 100 litros. De acordo com o trabalho de Leite Filha et al (2021), além dessas características construtivas, a configuração otimizada do coletor solar plano é: adição de uma telha de zinco ondulada pintada de preto fosco nas mesmas dimensões da base do coletor solar, que funciona como capacitor térmico, e cobertura transparente de policarbonato alveolar.

O coletor solar plano obtido está ilustrado na Figura 1. 
Figura 1 - Coletor solar plano otimizado por Leite Filha et al. 2021.
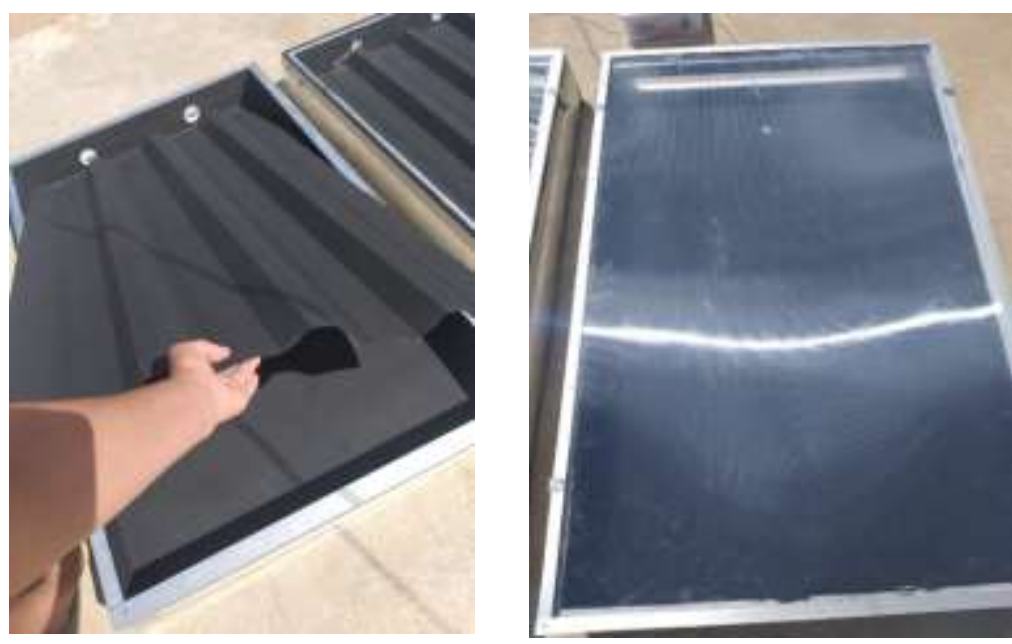

Fonte: Leite Filha (2021).

\subsection{Câmara de secagem e sistema de exaustão}

A câmara de secagem foi construída, assim como o coletor solar, com isopor e revestida de alumínio. Possui volume interno de 50 litros com dimensões de $0,80 \mathrm{~m}$ de largura por $0,45 \mathrm{~m}$ de comprimento por $0,14 \mathrm{~m}$ de altura.

$\mathrm{O}$ sistema de exaustão é composto por dois coolers de $0,08 \mathrm{~m}$ e $12 \mathrm{~V}$ acionados por um painel fotovoltaico de $12 \mathrm{~V}$.

$\mathrm{Na}$ câmara de secagem foi instalada uma bandeja feita de nylon e madeira com dimensões de $0,79 \mathrm{~m}$ de largura e 0,44 $\mathrm{m}$ de comprimento, totalizando uma área de $0,35 \mathrm{~m}^{2}$, aproximadamente. Nesta bandeja, foram dispostas as amostras de banana para a realização dos testes de secagem (Figura 2).

Figura 2 - Câmara de secagem e sistema de exaustão.
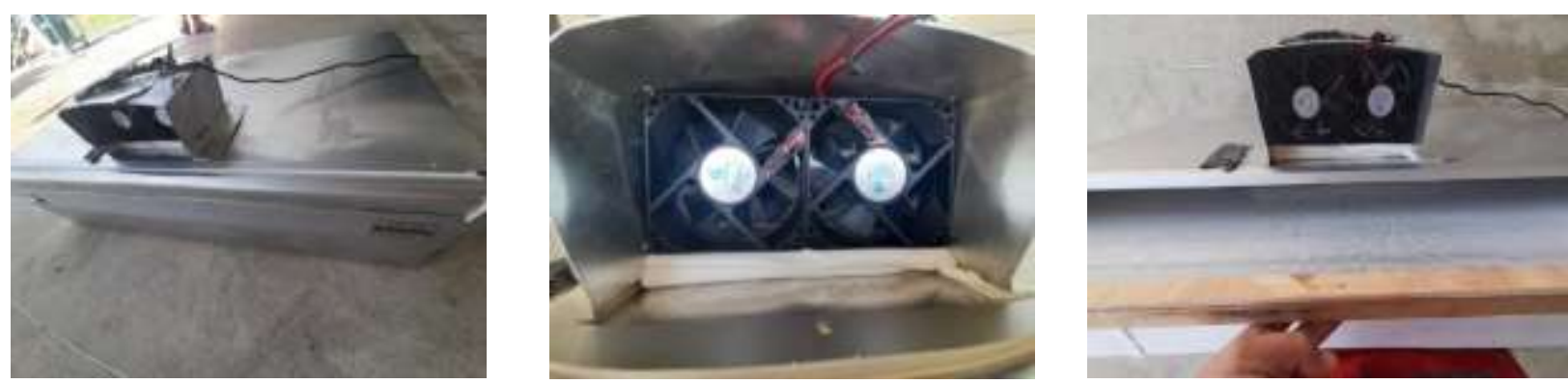

Fonte: Autor.

Os testes experimentais de secagem da banana prata foram realizados nas cidades de Campina Grande, PB nos meses de janeiro e julho de 2021 e em Pombal, PB nos meses de janeiro e março de 2021.

Os experimentos tiveram início às 08:00 h. Às 16:00 h o experimento é interrompido, devido queda na intensidade de incidência de radiação solar. Ao fim do primeiro dia de experimento as amostras são guardadas em embalagens hermeticamente fechadas e identificadas. $\mathrm{O}$ experimento é retomado no dia seguinte também às 08:00 h. Nenhum dos experimentos necessitou de mais de 2 dias para concluir o processo de secagem.

O processo de secagem é considerado concluído quando a média das massas das três amostras de apresentam teor de água de $25 \%$, em base úmida. As bananas utilizadas nos experimentos de secagem, possuíam teor de água inicial de, aproximadamente, $70,00 \%$. 
Os experimentos, denotados por E1, E2, E3 e E4, foram realizados, respectivamente, nos dias 18 e 19 de janeiro de 2021 e 07 e 08 de julho de 2021 em Campina Grande, PB, 24 e 25 de janeiro de 2021 e 26 e 27 de março de 2021 em Pombal, PB.

\subsection{Obtenção dos dados de temperatura e umidade relativa do ar}

Para a medição e aquisição dos dados de temperatura e umidade relativa do ar foram utilizados uma plataforma eletrônica de código aberto baseado em hardware e software (Tipo arduino) e sensores do tipo DHT22.

Os sensores de temperatura e umidade relativa do ar foram posicionados nos seguintes pontos:

- Entrada do coletor solar (mede-se: Temperatura do ar ambiente - Ta e Umidade relativa do ar ambiente - URa);

- Saída do coletor solar (mede-se: Temperatura do ar na saída do coletor solar - Ts e unidade relativa do ar na saída do coletor solar - URs);

Na Figura 3 é apresentado o secador solar desenvolvido e avaliado experimentalmente na secagem de banana prata.

Figura 3 - Secador solar desenvolvido e testado na secagem de banana prata.

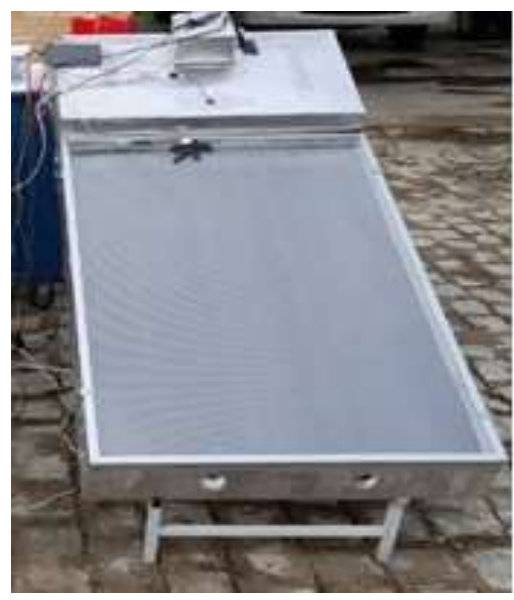

Fonte: Autor.

\subsection{A banana a ser desidratada}

A banana prata foi a fruta utilizada nos processos de secagem. Os frutos foram adquiridos no comércio popular na cidade de Pombal, PB, mesmos os que foram utilizados nos testes experimentais de secagem realizados na cidade de Campina Grande.

Para realizar a secagem, as bananas estavam em ponto de maturação para consumo sem apresentar danos físicos ou deterioração provenientes de insetos, foram higienizadas, descascadas e cortadas longitudinalmente com faca e aço inoxidável. As secagens foram realizadas em triplicata, onde cada uma das três amostras possuía massa inicial de $37,60 \mathrm{~g}+-0,05 \mathrm{~g}$.

Na Figura 4 é possível observar as amostras das fatias de banana prontas para a secagem. 
Figura 4 - Amostras de banana cortadas para a secagem.
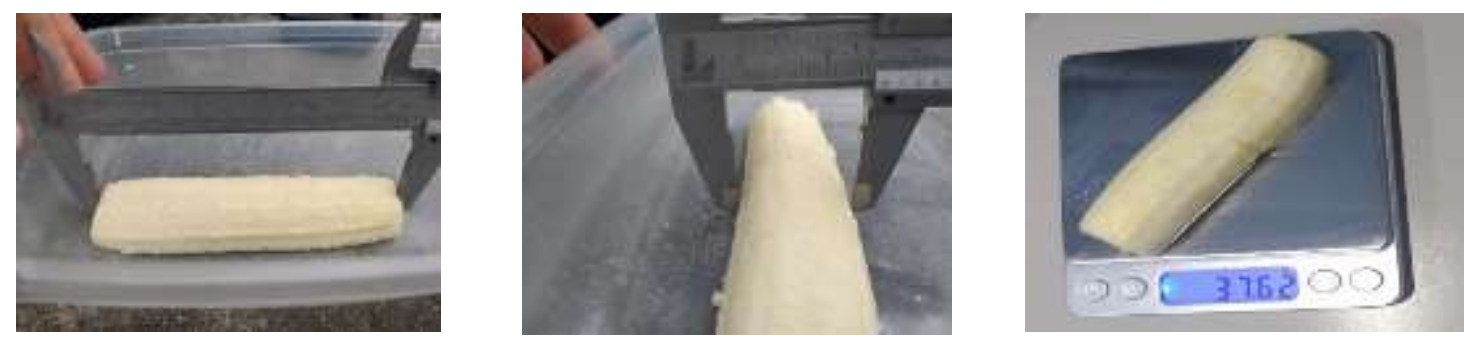

Fonte: Autor.

Ao término de cada experimento foi calculado a média da temperatura do ar de saída do coletor solar, chamada de temperatura média de secagem (Tmédia de secagem). As amostras secas foram levadas a estufa por 24 horas na Tmédia de secagem. Após esse tempo, as amostras são colocadas em dessecador por 2 horas, até atingir temperatura próxima à ambiente e são pesadas. Em seguida, são levadas novamente a estufa por mais 24 horas a temperatura de $70^{\circ} \mathrm{C}$. Ao término deste período, as amostras são levadas ao dessecador por 2 horas e após esse tempo nova pesagem é realizada para determinar o teor de água inicial das amostras.

As primeiras 24 horas de secagem na estufa servem para determinar o teor de água de equilíbrio da fruta e as últimas 24 horas servem para determinar sua massa seca.

\subsection{Obtenção dos dados de radiação solar térmica}

Campina Grande localiza-se na mesorregião do Agreste paraibano, nas coordenadas geográficas de $7^{\circ} 13^{\prime} 51^{\prime}$ 'Sul de latitude e 3552’54" Oeste de longitude. Já o município de Pombal está situado na área geográfica de abrangência do semiárido brasileiro, na mesorregião do Sertão paraibano, distante cerca de $250 \mathrm{~km}$ de Campina Grande, localizado nas coordenadas geográficas de 6 $46^{\prime} 13^{\prime}$ 'Sul de latitude de 3748’06” Oeste de longitude.

Os dados de radiação solar para os dias de experimentos realizados na cidade de Campina Grande foram obtidos na estação do INMET localizada nessa cidade, estação A313, fundada em 22/12/2006. Como na cidade de Pombal não há estação meteorológica que possa fornecer os dados de radiação solar incidente nos dias de realização dos experimentos, as estações mais próximas são as do Instituto Nacional de Meteorologia (INMET), instaladas nas cidades de São Gonçalo, PB (cuja

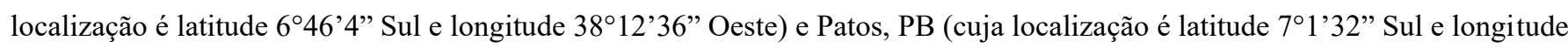
$37^{\circ} 16^{\prime} 40^{\prime \prime}$ Oeste).

Em São Gonçalo, fica a estação de código A333, fundada em 06/11/2007. Em Patos, está a estação de código A321, fundada em 21/07/2007. Além disso, a cidade de Pombal, fica entre estas duas cidades; assim, optou-se por calcular uma média entre os dados de radiação solar obtidos nestas duas estações nos dias de testes realizados em Pombal. Estes valores foram utilizados, por exemplo, para calcular o rendimento térmico dos equipamentos testados.

\subsection{Avaliação do secador solar}

A avaliação do secador solar foi feita a partir da determinação do rendimento térmico do coletor solar e do tempo médio de secagem.

Fudholi et al. (2014) testou um secador solar de exposição indireta, na secagem de pimenta vermelha, obtendo rendimento térmico médio do coletor solar de $28 \%$ e tempo médio de secagem de 33 horas.

Nunes (2016) testou um secador solar de exposição indireta construído de MDF Ultra, na secagem de banana prata, obtendo rendimento térmico médio do coletor solar de $21 \%$ e tempo médio de secagem de 14 horas. 
Lima (2017) testou um secador solar de exposição indireta construído de MDF Ultra, na secagem de banana prata, obtendo rendimento térmico médio do coletor solar de $29 \%$ e tempo médio de secagem de 14 horas.

Gomes (2021) testou um secador solar de exposição indireta construído de madeira de Pinus, na secagem de abacaxi, obtendo rendimento térmico médio de $20 \%$ e tempo médio de secagem de 16 horas.

\subsubsection{Rendimento térmico}

Segundo Nunes (2016) o desempenho ou a eficiência de um sistema de secagem solar está relacionado com seu rendimento térmico.

Para execução dos cálculos de rendimento térmico do coletor solar, aplicou-se o balanço de energia ao volume de controle estabelecido (Figura 5).

Figura 5 - Representação esquemática do volume de controle para o coletor solar.

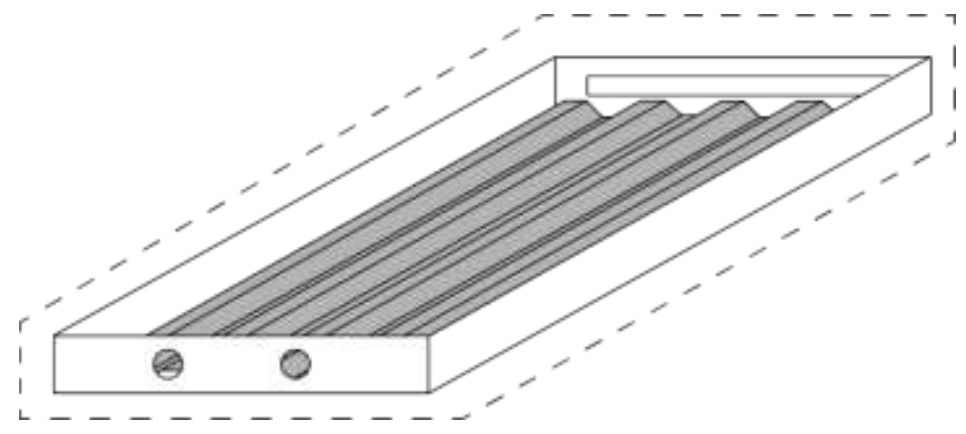

Fonte: Autor.

Aplicando o conceito de eficiência térmica, pela primeira e segunda leis da termodinâmica para o volume de controle chega-se à expressão que representa o rendimento térmico do coletor solar desenvolvido, dado pela Equação 1 .

$\eta_{\text {coletor }}=\eta_{\mathrm{lc}}=\frac{\mathrm{Q}_{\mathrm{real}}}{\mathrm{Q}_{\mathrm{solar}}}=\frac{\mathrm{m}\left(\mathrm{h}_{\mathrm{s}}-\mathrm{h}_{\mathrm{e}}\right)}{\mathrm{A} \cdot \mathrm{Q}_{\text {média }}}$

Onde:

m = Vazão mássica do fluido de trabalho $\left(\frac{\mathrm{kg}}{\mathrm{g}}\right)$;

$\mathrm{h}_{\mathrm{e}}=$ Entalpia específica do ar na entrada no volume de controle $\left(\frac{\mathrm{k}}{\mathrm{kg}}\right)$;

$\mathrm{h}_{\mathrm{s}}=$ Entalpia específica do ar na saída no volume de controle $\left(\frac{\mathrm{kJ}}{\mathrm{kg}}\right)$;

A = Área da cobertura transparente do secador solar $\left(\mathrm{m}^{2}\right)$;

$\mathrm{Q}_{\text {média }}=$ Média da irradiação solar, incidente sobre o secador solar, durante o processo de secagem $\left(\frac{W}{m^{2}}\right)$.

\subsubsection{Tempo de secagem}

O tempo de secagem é determinado a partir do teor de água das amostras de banana em base úmida. A Resolução da Diretoria Colegiada da ANVISA - Agência Nacional de Vigilância Sanitária, número 272, de setembro de 2005, determina que uma fruta é considerada fruta passa, ou fruta seca, quando possuir teor de água, em base úmida, de até $25 \%$.

As bananas utilizadas nos testes experimentais possuíam teor de água inicial médio, em base úmida, de $70 \%$. 


\section{Resultados e Discussão}

Foram realizados 4 testes experimentais nas cidades de Campina Grande e Pombal, ambas no estado da Paraíba. Estas cidades apresentam condições climáticas e meteorológicas diferentes, sendo Campina Grande, localizada no agreste paraibano, apresentando temperaturas mais amenas, umidades relativas do maior e incidência de radiação solar menor quando comparada a Pombal, localizada no sertão paraibano.

Os testes ainda foram realizados em períodos inverno e verão em cada cidade, de modo a testar o equipamento nas mais diversas condições possíveis.

Os dados de temperatura e umidade relativa do ar ambiente, de incidência de radiação solar e rendimento térmico do coletor solar e tempo de secagem dos experimentos E1, E2, E3 e E4 estão apresentados na Tabela 1.

Tabela 1 - Principais dados dos experimentos E1, E2, E3 e E4.

\begin{tabular}{l|c|c|c|c}
\hline & E1 & E2 & E3 & E4 \\
\hline Ta $\left({ }^{\circ} \mathrm{C}\right)$ & 32,8 & 26,3 & 43,0 & 34,5 \\
\hline $\mathrm{URa}(\%)$ & 45,5 & 55,0 & 30,0 & 53,2 \\
\hline $\mathrm{Q}_{\text {média }}\left(\mathrm{W} / \mathrm{m}^{2}\right)$ & 668 & 597 & 759 & 705 \\
\hline$\eta_{\text {coletor }}(\%)$ & 30,85 & 31,83 & 27,68 & 29,81 \\
\hline tsec $(\mathrm{h})$ & 15 & 16 & 11 & 12 \\
\hline
\end{tabular}

Fonte: Autor.

Os dados de decaimento de massa destes experimentos estão apresentados no Gráfico 1.

Gráfico 1 - Decaimento de massa da banana nos experimentos E1, E2, E3 e E4.

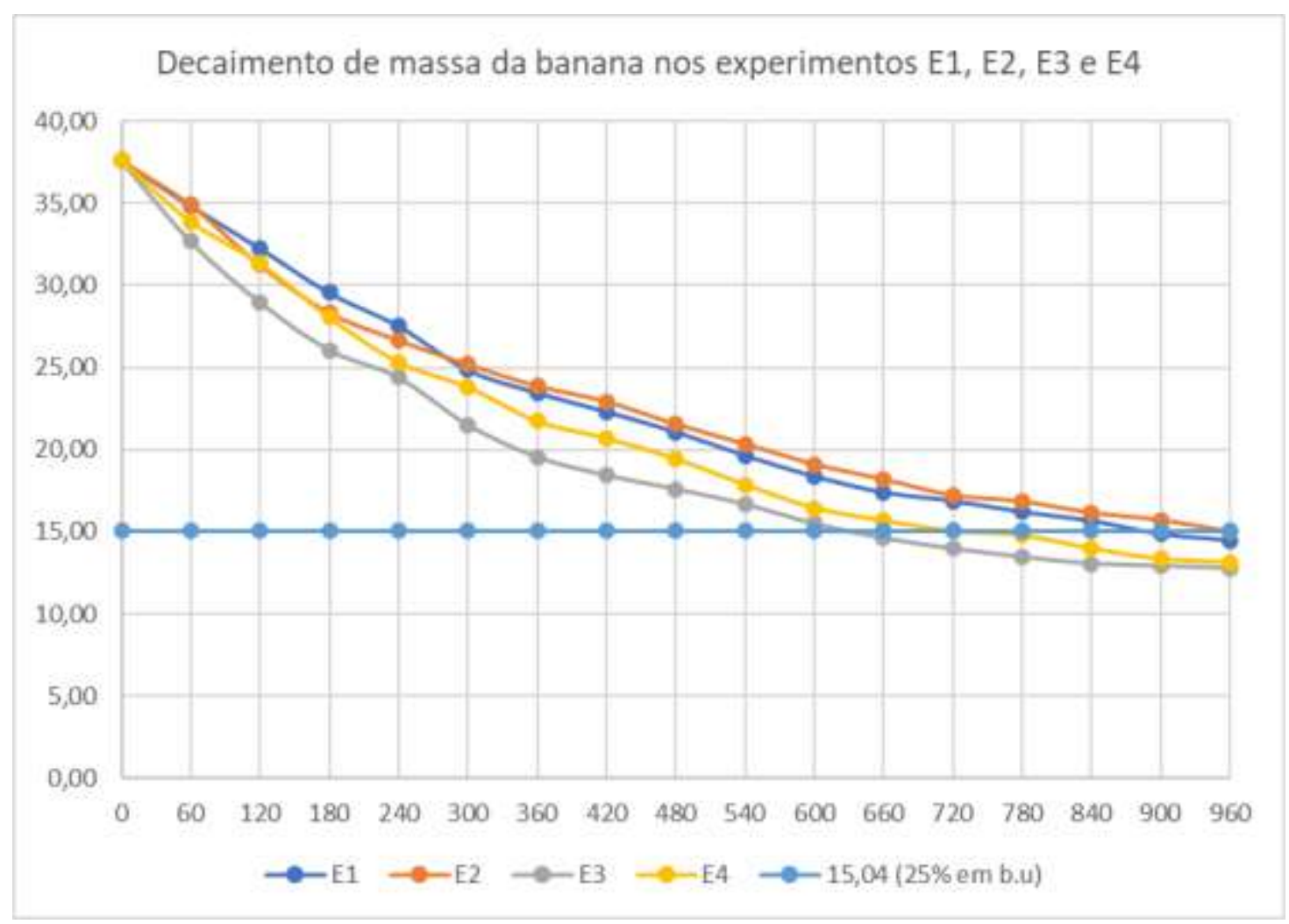

Fonte: Autor.

Como é possível a partir do Gráfico 1, o menor tempo de secagem foi obtido no experimento E3, realizado no verão em Pombal (11 horas), e o maior tempo de secagem foi obtido no experimento E2, realizado no inverno em Campina Grande 
(16 horas). O menor tempo de secagem coincide com os maiores valores de temperatura do ar ambiente e incidência de radiação solar e menor valor de umidade relativa do ar ambiente e, por sua vez, o maior tempo de secagem foi obtido coincide com os menores valores de temperatura do ar ambiente e incidência de radiação solar e maior valor de umidade relativa do ar ambiente.

Assim, pode-se observar a influência das condições do ar ambiente e da incidência de radiação solar no processo de secagem em secador solar de exposição indireta.

O tempo médio de secagem foi de 810 minutos (13 horas e 30 minutos). Valor similar a alguns reportados na literatura (Nunes, 2016 e Lima, 2017).

Quando se considera a cidade onde os experimentos foram realizados, tem-se que o tempo médio de secagem em Campina Grande de 930 minutos (15 horas e 30 minutos) e em Pombal de 690 minutos (11 horas e 30 minutos). Quando se considera o período do ano no qual os experimentos foram realizados, tem-se que o tempo médio de secagem no verão foi de 780 minutos (13 horas) e no inverno foi de 840 minutos (14 horas).

O rendimento térmico médio do coletor solar foi de $30,04 \%$. Os coletores apresentaram pequena variabilidade de eficiência (com valores entre 27,68\% e 31,83\%). Estes valores são similares a alguns reportados na literatura (Fudholi et al., 2014 e Lima, 2017).

Os experimentos realizados mostram a viabilidade técnica do secador solar desenvolvido, e que a operação de secagem pode ser realizada em diferentes configurações de condições climáticas e meteorológicas.

\section{Conclusão}

Com base nos testes experimentais de secagem solar, realizada em secador solar de exposição indireta, da banana prata, foi possível concluir que:

- O sistema de secagem desenvolvido foi capaz de utilizar a energia solar térmica para aquecer o ar ambiente e secar as amostras de banana.

- A banana passa, com teor de água máximo de $25 \%$ em umidade, em base úmida, foi obtido com um tempo médio de secagem 13,5 horas (treze horas e 30 minutos);

- O rendimento térmico médio do coletor solar foi de 30,04\%, o que está de acordo com o apresentado na literatura.

- O equipamento desenvolvido foi construído com materiais de baixo custo, facilmente encontrados no comércio local, como forma de garantir um equipamento que possa ter sua tecnologia disseminada e que atenda à demanda dos produtores das regiões do agreste e sertão paraibanos.

- Sua operação e manutenção foram executadas sem necessidade de ações de elevada complexidade, o que comprovam a possibilidade de sua construção e operação, tornando-o uma tecnologia apropriada para inserção no ambiente comercial.

- O secador solar desenvolvido é tecnicamente viável em comparação a resultados obtidos na literatura, sendo oportuno seu emprego para redução de perdas de alimentos e para oferta de produtos com maior valor agregado.

Ficam como sugestão de trabalhos futuros:

- Realizar testes experimentais com a capacidade máxima do secador solar;

- Ajustar modelos matemáticos de cinética de secagem aos dados experimentais obtidos (Page, Midilli et al. Exponencial, etc);

- Realizar testes experimentais com outros produtos como abacaxi, maçã. 
Research, Society and Development, v. 11, n. 1, e15411124405, 2022

(CC BY 4.0) | ISSN 2525-3409 | DOI: http://dx.doi.org/10.33448/rsd-v11i1.24405

\section{Referências}

ABRAFRUTA. (2019). Associação Brasileira dos Produtores Exportadores de Frutas e Derivados. www.abrafruta.org.

ANVISA. (2005). Agência nacional de Vigilância Sanitária. Resolução da Diretoria Colegiada (RDC), nº 272 de 22 de setembro de 2005.

Costa, A. R. S. (2008). Sistema de Secagem Solar para Frutos Tropicais e Modelagem da Secagem de Banana em um Secador de Coluna Estática. Tese de Doutorado. Programa de Pós-Graduação em Engenharia Química. Universidade Federal do Rio Grande do Norte, Natal.

Costa, N. L.; Leite Filha, M. de S.; Conceição, J. A. S. e S. da; Gomes, Í. A.; Santana, V. L.; Fernandes, J. F. de S.; Lima J. C. de; \& Grilo, M. B. (2021). Evaluation of a direct exposure solar drying system for pineapple under meteorological conditions in the northeastern semiarid region. Research, Society and Development. 10(8), e31910817399, 2021. 10.33448/rsd-v10i8.17399. https://rsdjournal.org/index.php/rsd/article/view/17399. Acesso em: 26 nov. 2021.

CRESESB (2019). Centro de referência em Energia Solar e Eólica Salvo Brito. Disponível em: www.cresesb.cepel.br.

FAO. (2017). Food and Agriculture Organizations of the United Nations. Pérdidas y desperdicios de alimentos em América latina y el Caribe: Boletín 4. Disponível em; www.fao.org.

Fernandes, J. F. S. (2021). Desenvolvimento experimental de um secador solar especial com sílica gel como dessecante do ar de secagem. Dissertação de mestrado. Programa de Pós-Graduação em Engenharia Mecânica, Universidade federal de Campina Grande, Campina Grande.

Fudholi, A.; Sopian, K., Yazdi, M. H.; Ruslan, M. H., Gabbasa, M.; \& Kazem, H. A. (2014). Performance analysis of solar drying system for red chili. Solar Energy. 99. 47-54, 2014.

Gomes, Í. A. (2021). Dimensionamento e Otimização de um Secador Solar de Frutas Utilizando o Método do Planejamento Experimental Fatorial. Tese de doutorado. Programa de Pós-Graduação em Engenharia de Processos, Universidade Federal de Campina Grande, Campina Grande.

IBGE. (2020). Instituto Brasileiro de Geografia e Estatística. https://www.ibge.gov.br/explica/producao-agropecuaria/banana/br.

Leite Filha, M. S., Silva, M. B., Gomes, I. A., Grilo, M. B., Costa, N. L., Conceição, J. A. S. S. S., Santana, V. L., \& Fernandes, J. F. S. (2021). Development of a flat solar collector for a drying system using factorial experimental design. Research, Society and Development. 10(7). e39010716755, 10.33448/rsdv10i7.16755. Disponível em: https://rsdjournal.org/index.php/rsd/article/view/16755.

Lima, A. G. B. (1999). Fenômeno de Difusão em Sólidos esferoidais Prolatos. Estudo de caso: secagem de banana. Tese de Doutorado. Programa de PósGraduação em Engenharia Mecânica. Universidade estadual de Campinas, Campinas.

Lima, W. S. (2017). Análise de Sistema de Secagem: solar, elétrico e misto na produção de banana passa. Tese de Doutorado. Programa de Pós-Graduação em Engenharia de Processos. Universidade Federal de Campina Grande, Campina Grande.

Nunes, A. G. (2016). Desenvolvimento Experimental de um Secador Solar Multienergético para Secagem de Frutas. Tese de Doutorado. Programa de PósGraduação em Engenharia de Processos. Universidade Federal de Campina Grande, Campina Grande.

Oliveira, L. C. T. G., Paes, J. L., \& Guimarães, C. L. (2018). Avaliação da eficiência do coletor solar plano acoplado em secador híbrido. VII Congresso Brasileiro de Energia Solar. Gramado-RS.

Silva, S. T \& Sousa, N. G. (2020). Uso da energia solar como fonte alternativa para o aquecimento de utilidades: simulação e controle. Research, Society and Development. 9(3). https://doi.org/10.33448/rsd-v9i3.2730 